\title{
Hybridization rates between lettuce (Lactuca sativa) and its wild relative ( $L$. serriola) under field conditions
}

\author{
Luigi D'ANDREA*, François FELBER and Roberto GUADAGNUOLO \\ Laboratoire de botanique évolutive, Institut de biologie, Université de Neuchâtel, Rue Émile-Argand 11, CP 158, 2009 Neuchâtel, \\ Switzerland
}

Hybridization and introgression between crops and wild relatives may have important evolutionary and ecological consequences such as gene swamping or increased invasiveness. In the present study, we investigated hybridization under field conditions between crop lettuce (Lactuca sativa) and its wild relative prickly lettuce (L. serriola), two cross-compatible, predominantly autogamous and insect pollinated species. In 2003 and 2004 , we estimated the rates of hybridization between $L$. sativa and $L$. serriola in close-to-reality field experiments carried out in two locations of Northern Switzerland. Seeds set by the experimental wild plants were collected and sown (44352 in 2003 and 252345 in 2004). Progeny was screened morphologically for detecting natural hybrids. Prior to the experiment, specific RAPD markers were used to confirm that morphological characters were reliable for hybrid identification. Hybridization occurred up to the maximal distance tested (40 $\mathrm{m}$ ), and hybridization rates varied between 0 to $26 \%$, decreasing with distance. More than $80 \%$ of the wild plants produced at least one hybrid (incidence of hybridization, IH) at $0 \mathrm{~m}$ and $1 \mathrm{~m}$. It equaled 4 to $5 \%$ at $40 \mathrm{~m}$. In sympatric crop-wild populations, cross-pollination between cultivated lettuce and its wild relative has to be seen as the rule rather than the exception for short distances.

Keywords: autogamy / hybridization / introgression / Lactuca sativa / Lactuca serriola / pollen flow / RAPD

\section{INTRODUCTION}

In the last decade, the extensive cultivation and commercialization of genetically engineered (GE) crops has exacerbated the arguments about crop-to-wild gene flow and its subsequent environmental effects. A major concern is the potential changes in the ecology of crop-related wild species, due to the introgression of transgenes into wild populations living in agricultural areas (Ellstrand, 2003; Wolfenbarger and Phifer, 2000). The introgression in a wild relative of a herbicide resistance gene could lead to increased invasiveness and/or weediness of introgressants (Snow and Palma, 1997), with a potentially negative impact for the cropping system (Klinger et al., 1991). Risks of gene swamping or pollution of natural gene pools, leading to the extinction of wild taxa have also been stressed (Ellstrand, 2003). These risks are thought to be higher if the wild plants show already weedy tendencies (Snow and Palma, 1997). In this context, Lactuca serriola is already described as an invasive weed in Canada and in Argentina, where it occurs in a variety of crops where notill or conservation tillage systems are used (Weaver and Downs, 2003), and in many European countries, where it occupies ruderal places (Lebeda et al., 2004). Interestingly enough, herbicide-resistant weedy populations

*Corresponding author: luigi.dandrea@natucom.ch of prickly lettuce have already been found in the United States and in Australia (International Survey of Herbicide Resistant Weeds, http://www.weedscience.org/in.asp).

The likelihood of (trans)gene escape increases when the flowering periods of a sexually reproducing crop and of its wild relatives overlap, and when no pre- or postzygotic barriers to hybridization exist. Both conditions are met for $L$. sativa and $L$. serriola, since the two species are closely related, and are even often considered as conspecific (De Vries, 1990; Lindqvist, 1960a; Whitaker, 1939). Crop lettuce differs from prickly lettuce only for characters connected to domestication, like rapid growth, short life-cycle, absence of dormancy, and generally absence of prickles on the leaves and on the stem (Frietema de Vries et al., 1994). Both species are diploid, and their chromosome length and genetic background are equivalent (Koopman et al., 2001; Lindqvist, 1960a). Selffertility prevails in L. serriola (Mejias, 1994) and is commonly regarded as being complete in L. sativa (Jones, 1927).

However, while the potential weedy character of prickly lettuce (Weaver et al., 2003), and its ability to hybridize with crop lettuce (Frietema de Vries et al., 1994) have been demonstrated, no data exist on the likelihood of such events. Intuitively, the chances for hybridization are low for such predominantly autogamous species. 
However, hybridization and introgression with locally adapted lettuce varieties could be one of the possible explanations of the rapid expansion of prickly lettuce towards northern Europe in the last century (Frietema de Vries, 1992). Moreover, recent studies have shown that low outcrossing rates do not prevent cultivated genes from moving in sympatric wild populations. These studies include both, autogamous and/or predominantly insect-pollinated species like soybean, bean or cotton (Ibarra Perez et al., 1997; Nakamaya and Yamaguchi, 2002; Van Deynze et al., 2005), as well as windpollinated autogamous species as rice or foxtail millet (Chen et al., 2004; Song et al., 2003; Wang et al., 1997; Zhang et al., 2003).

Plant breeders have long been concerned by cropto-crop and wild-to-crop hybridizations. In particular, studies on seed purity produced considerable data on hybridization rates, pollen dispersal, and on isolation distances required to minimize it (Bateman, 1947). Durst (1930) found that cross-fertilization in L. sativa is a rare event. Thompson et al. (1958) observed about $1 \%$ crosspollination between different lettuce varieties grown in adjacent rows (spaced of $1.2 \mathrm{~m}$ ) and an average amount of cross-pollination of $2.9 \%$ for one variety surrounded by plants of another one. Watts (1958) found that L. sativa plants flowering late in the season exhibited a significant increase in the percentage of cross-pollination, and explained this observation by a seasonal increase in the hover-fly population. Pollinators contribute substantially to the effective transfer of pollen to the stigma, within, and between capitula (Watts, 1958). Moreover, they have an influence on seed set (Mejias, 1994). Not surprisingly, distance and pollinator availability have been found to be the most relevant factors for pollen migration between different $L$. sativa varieties (Goubara and Takasaki, 2003; 2004; Thompson et al., 1958). While wild $\times$ crop hybridization cannot be inferred directly from the results presented above, we can assume that the main factors influencing the pollination of prickly lettuce by the crop are the same, since the species are very closely related. F1 hybrids are easily produced and completely fertile, irrespective of the species acting as the female parent (De Vries, 1990; Lindqvist, 1960a). Yet, in order to assess the risk of gene transfer from GE or conventional crop to wild relative, quantifying potential hybridization is a key issue.

Therefore, our study aims (1) to estimate the rate of hybridization and the incidence of hybridization between $L$. sativa and $L$. serriola in field conditions; (2) to evaluate the frequency of wild individuals setting at least one hybrid seed (incidence of hybridization); and (3) to evaluate the influence of distance on these parameters. Relevance of our results for the cultivation of GE lettuce and for lettuce breeding is highlighted.

\section{RESULTS}

\section{Hybridization rate (HR)}

In 2003, the highest individual hybridization rate (HR) was observed at $1 \mathrm{~m} \mathrm{(26 \% )}$ and $0 \mathrm{~m}(16 \%)$ in Bevaix, and at $1 \mathrm{~m}$ in Séprais $(12 \%$ and $14 \%)$. As expected, the mean HR also reached high levels: $7.4 \%$ at $1 \mathrm{~m}$, or $3 \%$ at $5 \mathrm{~m}$. In 2004, the HR values were lower than those obtained in 2003. The HR decreased exponentially as a function of the logarithm of the distance (Fig. 1). Individual HR varied considerably between plants, ranging from 0 to $12 \%$ at $0 \mathrm{~m}$, from 0 to $3.15 \%$ at $1 \mathrm{~m}$, from 0 to $0.56 \%$ at $5 \mathrm{~m}$, from 0 to $0.29 \%$ at $15 \mathrm{~m}$, from 0 to $1.33 \%$ at $25 \mathrm{~m}$ and from 0 to $0.11 \%$ at $40 \mathrm{~m}$. Overall, the mean $\mathrm{HR}$ varied between $1.9 \%$ and $2.75 \%$ within the cultivated plot, and between 0.69 to $0.74 \%$ at $1 \mathrm{~m}$. It was lower than $0.15 \%$ at longer distances. Finally, mean HR was greater than zero at all distances and in both field sites (Tab. 1).

\section{Incidence of hybridization (IH)}

In 2004, the IH decreased as a function of the distance (Fig. 2), but not as drastically as the HR. In 2004, most of the wild plants produced at least one hybrid at $0 \mathrm{~m}$ in trials 1 and 2 (87\% and 94\% respectively) and at $1 \mathrm{~m}$ ( $82 \%$ and $97 \%$ ) (Tab. 2). At $5 \mathrm{~m}$, the IH was $32 \%$ in trial 1 and $62 \%$ in trial 2, while it was 5 and $21 \%$ respectively at $15 \mathrm{~m}$. Surprisingly, the IH was higher at $25 \mathrm{~m}$ than at $15 \mathrm{~m}$ (except for trial 2 South). Finally, 4 and $5 \%$ of the mother plants produced hybrids at $40 \mathrm{~m}$.

\section{Statistical results}

For trial 1, the IH was globally significantly higher in 2003 than in $2004(P<0.05)$, while for trial 2 , the HR was significantly higher in 2003 than in $2004(P<0.05)$. However, because of the lack of data, no within- or between-sites comparisons could be done for the 2003 experiment.

In 2004, the HR did not differ significantly between field sites, but a significant difference was observed between North $v s$. South lines in field trial 1 (Bevaix, $P<$ $0.0019)$. On the contrary, the number of plants possessing at least one hybrid in their progeny $(\mathrm{IH})$ was significantly higher in trial 1 than in trial $2(P<0.0083)$, while no differences due to the orientation were observed within field sites (Tab. II).

Finally, no effect of the prickly lettuce population was observed, neither on HR, nor on IH $(P>0.05$, results not shown). 
Hybridization between cultivated lettuce and its wild relative

Table 1. Survival, mean hybridization rates (MHR, in \%) and incidence of hybridization (IH, in \%) of the experimental wild plants, in the two field sites and orientations (North-South), as a function of the distance from the crop pollen source (data of the 2004 experiment). D: distance from pollen source (m); S: number of surviving plants; MHR: average hybridization rate (\%); SD: standard deviation.

\begin{tabular}{|c|c|c|c|c|c|c|c|c|}
\hline $\begin{array}{l}\begin{array}{l}\text { Field site } \\
\text { (orientation) }\end{array} \\
\text { (a) }\end{array}$ & D & $\mathbf{S}$ & $\begin{array}{l}\text { Grown } \\
\text { progeny } \\
(N \text { ind. })\end{array}$ & $\begin{array}{c}\text { Detectedhybrids } \\
\text { hybrids }\end{array}$ & MHR & $\begin{array}{c}\text { Individual } \\
\text { hybridization } \\
\text { rate range }\end{array}$ & SD & IH \\
\hline Trial 2 North & 0 & 12 & 9300 & 196 & 2.75 & $(0-9.83)$ & 3.1 & 92 \\
\hline \multirow[t]{5}{*}{ (2004) } & 1 & 18 & 16875 & 100 & 0.69 & $(0.1-3.11)$ & 0.69 & 100 \\
\hline & 5 & 16 & 16425 & 19 & 0.12 & $(0-0.56)$ & 0.17 & 44 \\
\hline & 15 & 16 & 16800 & 2 & 0.01 & $(0-0.1)$ & 0.03 & 13 \\
\hline & 25 & 12 & 12450 & 7 & 0.06 & $(0-0.44)$ & 0.13 & 33 \\
\hline & 40 & 12 & 11700 & 1 & 0.009 & $(0-0.1)$ & 0.029 & 8 \\
\hline Trial 2 South & 0 & 12 & 10395 & 226 & 1.9 & $(0-5.11)$ & 1.6 & 75 \\
\hline \multirow{5}{*}{ (2004) } & 1 & 17 & 15487 & 109 & 0.72 & $(0-3)$ & 0.68 & 94 \\
\hline & 5 & 16 & 14587 & 20 & 0.14 & $(0-0.36)$ & 0.11 & 81 \\
\hline & 15 & 17 & 17250 & 6 & 0.03 & $(0-0.19)$ & 0.056 & 29 \\
\hline & 25 & 18 & 13155 & 2 & 0.02 & $(0-0.25)$ & 0.06 & 11 \\
\hline & 40 & 18 & 5820 & 0 & 0 & 0 & 0 & \\
\hline Trial 2 overall (\%) & 0 & 67 & & & 2.33 & & & 87 \\
\hline \multirow{5}{*}{ (2004) } & 1 & 97 & & & 0.71 & & 97 & \\
\hline & 5 & 89 & & & 0.13 & & & 62 \\
\hline & 15 & 92 & & & 0.02 & & & 21 \\
\hline & 25 & 83 & & & 0.04 & & & 22 \\
\hline & 40 & 83 & & & 0.0045 & & & 4 \\
\hline Overall survival & & 85 & & & & & & \\
\hline Trial 1 North & 0 & 16 & 14400 & 297 & 2.21 & $(0.17-12.27)$ & 2.82 & 100 \\
\hline \multirow{5}{*}{ (2004) } & 1 & 11 & 7237 & 36 & 0.7 & $(0-3.15)$ & 0.91 & 82 \\
\hline & 5 & 14 & 6750 & 6 & 0.04 & $(0-0.22)$ & 0.09 & 21 \\
\hline & 15 & 1 & 375 & 0 & 0 & 0 & 0 & \\
\hline & 25 & 12 & 3075 & 2 & 0.11 & $(0-1.33)$ & 0.39 & 8 \\
\hline & 40 & 12 & 5550 & 0 & 0 & 0 & 0 & \\
\hline Trial 1 South & 0 & 18 & 13350 & 359 & 2.56 & $(0-8.67)$ & 2.72 & 89 \\
\hline \multirow{5}{*}{ (2004) } & 1 & 12 & 8775 & 42 & 0.74 & $(0-2.67)$ & 0.93 & 83 \\
\hline & 5 & 9 & 6075 & 7 & 0.11 & $(0-0.38)$ & 0.15 & 44 \\
\hline & 15 & 10 & 6225 & 3 & 0.03 & $(0-0.29)$ & 0.09 & 10 \\
\hline & 25 & 12 & 9563 & 3 & 0.03 & $(0-0.27)$ & 0.08 & 16 \\
\hline & 40 & 15 & 10725 & 1 & 0.007 & $(0-0.11)$ & 0.03 & 6 \\
\hline \multirow[t]{6}{*}{ Trial 1 overall (\%) (2004) } & 0 & 94 & & & 2.39 & & & 94 \\
\hline & 1 & 64 & & & 0.72 & & & 82 \\
\hline & 5 & 64 & & & 0.08 & & & 32 \\
\hline & 15 & 31 & & & 0 & & & 5 \\
\hline & 25 & 67 & & & 0.07 & & & 12 \\
\hline & 40 & 75 & & & 0.0035 & & & 3 \\
\hline Overall survival & & 6 & & & & & & \\
\hline
\end{tabular}




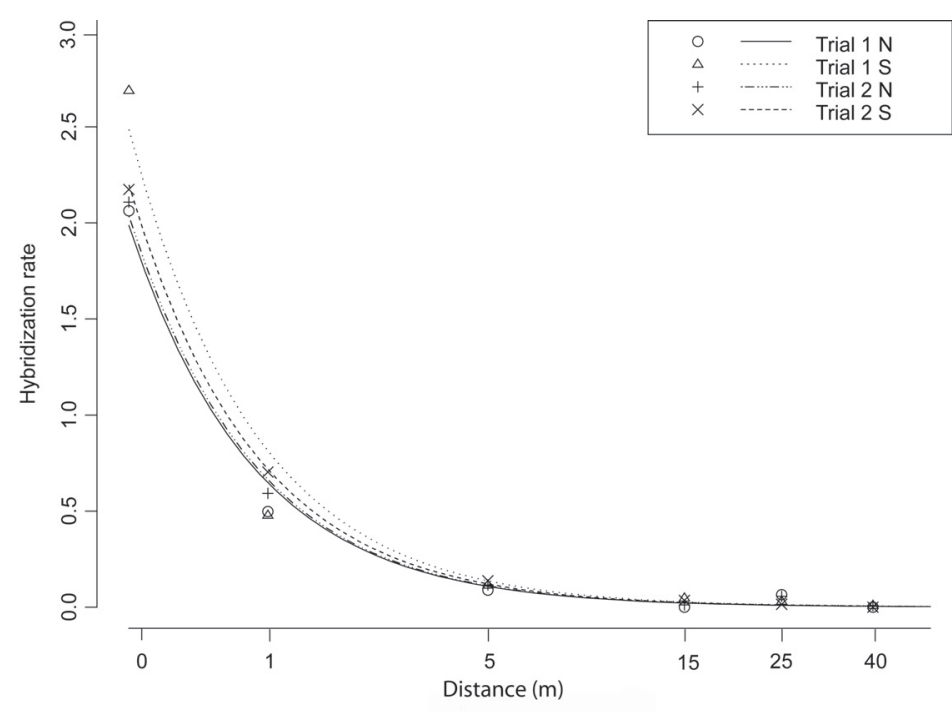

Figure 1. Mean hybridization rates (HR) (\%), represented as a function of the distance. The HR is the percent hybrid seeds.

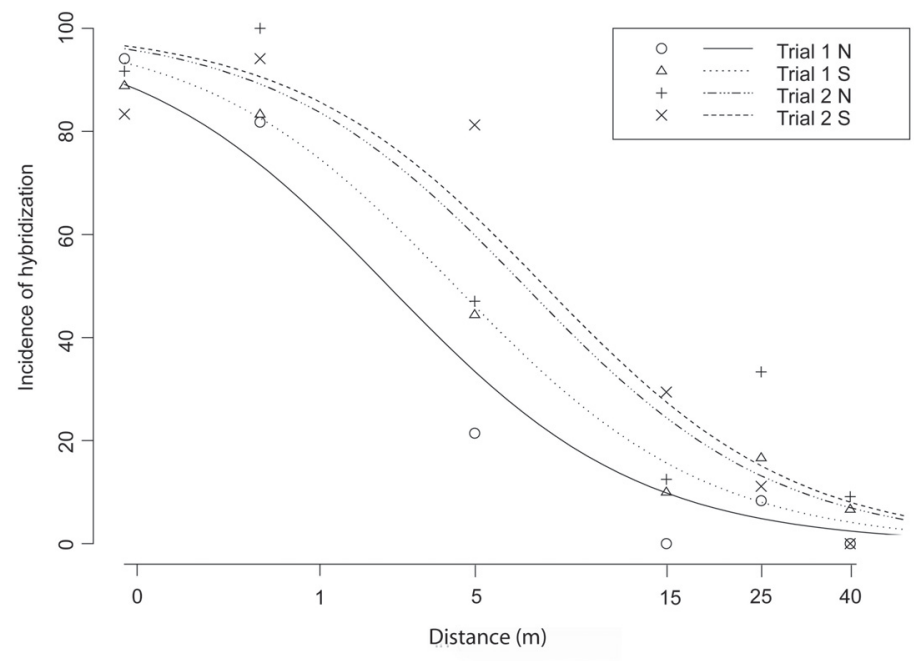

Figure 2. Incidence of hybridization (IH) (\%), represented as a function of the distance. The $\mathrm{IH}$ is the percent plants bearing at least one hybrid seed.

\section{Pollinators}

A total of 12 insect species were captured on Lactuca flowers (Tab. 3). All of them were generalist pollinators and belonged to Hymenoptera or Diptera. Temporary foraging as well as continual pollen gathering behaviors were observed. Generally speaking, insects tended to move from one capitula to another on a single plant, before moving to a different plant. In trial 2, where more flowering plants were present, more pollinators were observed, but in both trials, the highest density of pollinators was found in the crop plot.

\section{DISCUSSION}

Crop and prickly lettuce can hybridize at a higher than expected rate, considering that the species possess mechanisms favoring self-pollination. Moreover, hybridization can reach substantial levels, even at a relatively long distance. The importance of crop-wild lettuce hybridization has consequences for the environmental risk assessment of the cultivation of GE crops. Hence, the results and the experimental design need to be discussed and compared, relative to the context of current cultivation of crop lettuce. 
Hybridization between cultivated lettuce and its wild relative

Table 2. Analysis of maximum likelihood estimates.

\begin{tabular}{|c|c|c|c|c|c|}
\hline Parameter & $\mathrm{DF}$ & $\begin{array}{c}\text { Estimate } \\
\text { error }\end{array}$ & $\begin{array}{c}\text { Standard } \\
\text { Chi-Square }\end{array}$ & Wald & $\operatorname{Pr}>$ Chi-Square \\
\hline \multicolumn{6}{|c|}{ Hybridization rate } \\
\hline Intercept & 1 & -3.8352 & 0.0432 & 7868 & $<0.0001$ \\
\hline Site & 1 & 0.0511 & 0.0545 & 0.8820 & 0.35 \\
\hline logdist & 1 & -1.6350 & 0.0530 & 952.1 & $<0.0001$ \\
\hline \multicolumn{6}{|l|}{ Bevaix } \\
\hline North/South & 1 & 0.1145 & 0.0369 & 9.612 & 0.0019 \\
\hline \multicolumn{6}{|l|}{ Seprais } \\
\hline North/South & 1 & 0.0394 & 0.0385 & 1.047 & 0.31 \\
\hline \multicolumn{6}{|c|}{ Incidence of hybridization } \\
\hline Intercept & 1 & 3.2691 & 0.3976 & 67.61 & $<0.0001$ \\
\hline Site & 1 & -0.8994 & 0.3409 & 6.963 & 0.0083 \\
\hline logdist & 1 & -1.5580 & 0.1531 & 103.6 & $<0.0001$ \\
\hline \multicolumn{6}{|l|}{ Bevaix } \\
\hline North/South & 1 & 0.2662 & 0.2539 & 1.100 & 0.29 \\
\hline \multicolumn{6}{|l|}{ Seprais } \\
\hline North/South & 1 & 0.0792 & 0.2057 & 0.1483 & 0.70 \\
\hline
\end{tabular}

Table 3. Lactuca pollinator.

\begin{tabular}{lccc}
\hline \hline Order & Family & Genus & Species \\
\hline Hymenoptera & Apidae & Apis & mellifera \\
Hymenoptera & Apidae & Bombus & lapidarius \\
Hymenoptera & Andrenidae & Andrena & sp. \\
Hymenoptera & Halictidae & Halictus & sp. \\
Hymenoptera & Halictidae & Lasioglossum & sp. \\
Hymenoptera & Vespidae & Vespula & vulgaris \\
Hymenoptera & Sphecidae & Ectemnius & continuus \\
Diptera & Syrphidae & Episyrphus & balteatus \\
Diptera & Syrphidae & Chrysotoxum & elegans \\
Diptera & Syrphidae & Sphaerophoria & scripta \\
Diptera & Syrphidae & Scaeva & pyrastri \\
Diptera & Syrphidae & Syrphus & vitripennis \\
\hline
\end{tabular}

In most parts of Europe, crop fields and private vegetable gardens are often surrounded by ruderal habitats, where prickly lettuce commonly occurs at close distances from the crop. Moreover, both species have long blooming periods, which naturally overlap for many weeks. In $2005,10 \%$ of the Swiss production of the two most cultivated cultivars (mainly head type) was not harvested, due to the low prices of lettuce on the market (information gathered at the Swiss central of gardening market, Bern).
In those cases, cultivated plants are left in the field, and can bolt and flower close to wild populations of $L$. serriola. This represents 140 ha in Switzerland that could potentially hybridize with the wild species. It seems realistic then to consider our experimental conditions as intermediate between that of few cultivated lettuce bolting in private gardens and that of large-scale lettuce cultivation, where some plants are not harvested and left in the field. Therefore, suitable conditions for hybridization in agro-ecosystems seem to be frequently met in central and southern European countries.

\section{Natural hybridization}

Significant levels of hybridization between $L$. sativa and $L$. serriola were found. It clearly indicates crop-towild hybridization in the lettuce complex despite mechanisms ensuring a high degree of self-fertilization (Mejias, 1994). The mean HR values were comparable to outcrossing frequencies of lettuce varieties observed by Thompson et al. (1958) and Watts (1958). HR varied greatly between plants; however no evidence of a population effect could be detected. More likely, between-plant differences in HR depend on environmental factors such as climatic condition and pollinator abundance or on genetic traits influenced by environmental conditions like the induction of flowering (Prince et al., 1978). 


\section{D'Andrea et al.}

Not surprisingly, the mean HR per row decreased with the distance from the crop plot. Higher mean HRs were detected within the crop plot ( $0 \mathrm{~m}$ distance) or at short distances. Individual HR followed the same trend, with values lower than $0.6 \%$ at distances farther than $5 \mathrm{~m}$, but hybridization was still detected at $40 \mathrm{~m}$. These results are not surprising, since the crop pollen source was the most attractive sector of the field trials for the pollinators, because of the high density of flowers.

Results of both field locations were consistent; no influence of the location was found on the HR values, which could indicate that hybridization between the two species is possible when the two species occur in sympatry. The observation of generalist insect species all over the Swiss Plateau and Jura mountains foraging on the crop and its wild relative, supports this view.

Most of the plants that possessed extremely high HR values in 2003 and 2004 suffered from drought or from competition. They presented a scrawny phenotype, produced few flowers and consequently few seeds. These plants possibly also produced a lower amount of pollen. Environmental stresses can influence pollen performance (Snow and Spira, 1996), and temperature significantly influences positively in vivo pollen germination in cultivated lettuce (Eenink, 1983). Therefore, the lower amount of pollen produced by some wild plants, combined with the availability of crop pollen, could have facilitated the formation of hybrids. However, this latter point must be assessed.

\section{Incidence of hybridization}

Our results indicated that the IH decreased with distance, but less drastically than observed for the HR values. The $\mathrm{IH}$ values were significantly higher in trial 2 , compared to trial 1; while the HR values were similar. The HR is probably influenced by the amount of crop pollen carried by insects, while the $\mathrm{IH}$ is more influenced by their abundance. Our observations on the abundance of pollinators and their activity are purely qualitative and addressed only trial 2 . However, it is likely that the higher floristic diversity of this latter location, and consequently the higher number of flowers surrounding the experimental plants, were more attractive for generalist pollinators, and could explain the differences observed between sites for $\mathrm{IH}$.

For both field trials, the IH ranged between 80 and $100 \%$ for plants growing at distance up to $1 \mathrm{~m}$. These results are much higher than those found in the selffertilizing and insect pollinated crop-wild soybean complex (Nakamaya et al., 2002). Interestingly, our results are only slightly lower than those found in the outcrossing and insect pollinated crop-weed radish complex (Klinger et al., 1992), and higher than those found between mixedmating and insect-pollinated tobacco cultivars (Paul et al., 1995). At farther distances, the IH varied greatly, but frequencies as high as $81 \%$ at $5 \mathrm{~m}, 29 \%$ at $15 \mathrm{~m}$ or $33 \%$ at $25 \mathrm{~m}$ were found. These high values indicate that a single wild plant growing in proximity of blooming cultivated lettuce has high chances to produce hybrids.

Yet, our empirical data are clearly related to specific experimental conditions, like environmental year effect and experimental design. The fact that the recipient plants were placed in rows produced a shielding effect that probably underestimates the HR at far distances. However, we think that these data are relevant for Europe. First, the general picture arising from the results of the two sites and of the two years are congruent. Second, the pollinators captured are generalist European species, and their abundance was influenced experimentally neither by growing attractive flowers, nor by placing beehives. Third, the distances tested in our experiment are the most frequently observed in central European agroecosystems, where prickly lettuce grows along roads and railways close to or at the edge of cultivated fields.

\section{Importance of pollinators for gene flow in lettuce}

The importance of pollinators for the effective pollination of Lactuca flowers has already been demonstrated (Goubara et al., 2003; 2004). Jones (1927), showed that bagged flowers of $L$. sativa had significantly less or no pollen grains on their inner stigmatic surfaces, compared to open-pollinated flowers. He concluded that crosspollination between plants may be much more frequent than was formerly supposed. Mejias (1994) showed that freely pollinated flower heads always had a higher seed set than flower heads bagged before anthesis. Since pollinators ensure both self- and cross-pollinations, especially if crop and wild plants are visited alternately, their pollen gathering behavior can largely affect hybridization in lettuce.

Although this aspect could not be tested in our experiment, the distance to which pollen can be transferred between plants, and thus $\mathrm{HR}$ and $\mathrm{IH}$, seems to be highly dependent on the factors that can affect pollinator guilds and their foraging strategies. These factors include the number of flowers produced per plant, the seasonal or annual changes in meteorological conditions, the spatial patterns of distribution of the wild population, and their position relative to the crop pollen source (Schmitt, 1983; Van Deynze et al., 2005). Insect visitation rates and therefore possible hybridization rates might depend on the amount of flowers available from Lactuca, but surely also on the availability of other plant species, since all observed visitors were generalists. The exceptionally high individual HR, as well as the higher HR in trial 2 and the 
higher IH in trial 1 observed in 2003, might be due to the absence of other food sources for pollinators. It can also be explained by an increased activity of the pollinators, due to particularly warm and dry conditions observed in 2003.

\section{Hybrid characteristics and relevance for GE lettuce cultivation}

We clearly showed that the two species can hybridize easily, which represents the first step toward the understanding of the mechanisms of gene flow. In addition, even if no transgenic variety has been commercialized yet, $L$. sativa has already been engineered for many traits such as herbicide resistance (McCabe et al., 1999; Nagata et al., 2000), pathogen resistance (Okubara et al., 1997) and other agronomic traits (Curtis et al., 1999; Goto et al., 2000; Pileggi et al., 2001). Although we did not investigate crop-wild lettuce hybridization using transgenic varieties, our results have clear implications for the risks assessment of their cultivation.

While F1 hybrids can be easily distinguished morphologically from their wild parents at the rosette stage, differences at the adult stage are less evident. Natural hybrids and introgressants could then be more frequent than previously thought, based on their morphology only. Indeed, only a few old reports exist on the hybridization between $L$. serriola and L. sativa (McCollum (1953) in Lindqvist, 1960c; Ownbey and Andersson, 1949; Pammel, 1918). However, hybridization is an ongoing process, and natural hybrids between these two species can be found (personal observation, data not shown). Even rare hybridization events could have important consequences on the introgression of conventional and/or GE traits. One plant of $L$. serriola can easily produce from 10000 to 100000 seeds (personal observation). Consequently, a hybridization rate of $0.1 \%$, as observed for one plant located at $40 \mathrm{~m}$ from the crop, corresponds to 10 to 100 viable hybrid seeds produced. The F1 hybrids could combine the adaptations to wild habitats of the wild parent and those to the agro-ecosystems of the cultivated parent and be positively selected (Ladizinsky, 1984). The hybrids perform well in ruderal habitats and show heterosis in size and seed-set. Moreover, second-generation hybrids are as fit as the wild plants (Hooftman et al., 2005; 2007; Lindqvist, 1960a) which leads to successful introgression even in absence of continued hybridization. This situation relates to that of the maize-teosinte complex, where the pollen of the hybrid is as fit as that of the parents, and can easily pollinate the wild parent (Guadagnuolo et al., 2006).

Since the hybrid involucral bracts reflex at maturity and seeds scatter similarly to $L$. serriola, seed dispersal is not expected to differ from that of the wild parent.
Seed dispersal by human activities, which is mainly by vehicles, should not differ either (Lebeda et al., 2001, see also Snow et al., 1997). Finally, in case of commercialization of transgenic lettuce varieties, the containment of transgenes will be very difficult if not impossible, unless measures are taken to prevent bolting.

\section{MATERIALS AND METHODS}

\section{Field trials}

Our hybridization experiments were performed in field conditions using the same experimental design in 2003 and 2004, in two locations of northern Switzerland. Field trial 1 was located in Bevaix (canton Neuchâtel) $\left(46^{\circ} 56^{\prime} \mathrm{N}, 6^{\circ} 49^{\prime} \mathrm{E}\right)$ and field trial 2 in Séprais (canton Jura) $\left(47^{\circ} 20^{\prime} \mathrm{N}, 7^{\circ} 12^{\prime} \mathrm{E}\right)$. Both experimental plots were oriented North-South and possessed similar climatic conditions. They presented different topography and ecology. In trial 1, a steep slope separated the northern-upper part from the southern flat part; vegetation was typical grassland. Trial 2 was located on a homogenous slope in a typical meagre pasture. The floristic richness was greater in trial 2 than in trial 1 (data not shown).

\section{Experimental design}

In the middle of each field trial, a $25 \mathrm{~m} \times 1 \mathrm{~m}$ plot was used as crop pollen source and was planted with 400 L. sativa plants, distributed in four rows (Fig. 3). One-hundred individuals of the four different varieties were planted alternately. Spacing between plants was $25 \mathrm{~cm}$. L. serriola individuals were planted in 12 parallel rows, 6 North and 6 South at respectively $0 \mathrm{~m}, 1 \mathrm{~m}$, $5 \mathrm{~m}, 15 \mathrm{~m}, 25 \mathrm{~m}$ and $40 \mathrm{~m}$ of the pollen source. A two compass direction experiment was chosen, due to space limitation. Each row consisted of six plants of each of three populations at $1 \mathrm{~m}$ distance. Position of the populations along the row was random. The maximal distance of $40 \mathrm{~m}$ was chosen because (1) the aim of the study was to detect changes in the hybridization rates and incidence of hybridization at close distances from the crop; (2) the species were supposed to present a high degree of autogamy; therefore the hybridization rate at greater distances was expected to be too low for a reliable test; and (3) up to now, the only field trials carried out on $L$. sativa varieties tested the maximal distance of $1.2 \mathrm{~m}$. The experimental setup corresponds to the situation most frequently met in agro-ecosystems, where prickly lettuce grows at the edge of cultivated fields or along railways or roads that run parallel to them. 


\section{D'Andrea et al.}

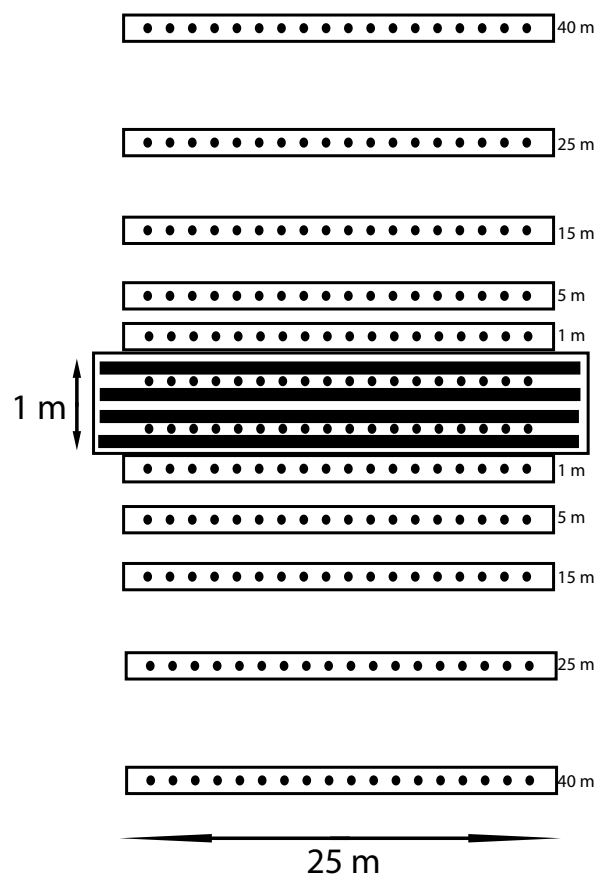

Figure 3. Experimental design used in both field trials. $(\bullet)$ represent an individual of $L$. serriola; 18 wild plants from three different populations randomly distributed at $1 \mathrm{~m}$ intervals in a row. Twelve rows were planted, 6 North and 6 South (at $0 \mathrm{~m}$, $1 \mathrm{~m}, 5 \mathrm{~m}, 15 \mathrm{~m}, 25 \mathrm{~m}, 40 \mathrm{~m}$ ) of a central $1 \mathrm{~m}$ wide, $25 \mathrm{~m}$ long source of crop pollen. Thick black lines in the middle represent the 4 rows of $L$. sativa (100 plants per row).

\section{Plant material}

We planted 400 L. sativa plants of four different conventional non-transgenic cultivars as local pollen source: Reine de mai (butterhead lettuce with green leaves), Laitue de Morges (romaine lettuce, with dark leaves), Laitue de St-Blaise (romaine lettuce, with green leaves), Feuille de chêne rouge (leaf lettuce with red leaves). Three different wild populations of $L$. serriola collected in southern Germany (LBM5: 9 ${ }^{\circ} 08^{\prime} \mathrm{E}, 4^{\circ}{ }^{\circ} 83^{\prime} \mathrm{N}$; D20: $\left.8^{\circ} 61^{\prime} \mathrm{E}, 48^{\circ} 18^{\prime} \mathrm{N}\right)$ and northern Switzerland (CH18: $8^{\circ} 76^{\prime} \mathrm{E}, 47^{\circ} 50^{\prime} \mathrm{N}$ ) were used as pollen sink. All the plants were sown and grown to a rosette stage in the Botanical Garden of Neuchâtel and then planted in the field.

In both trials, in 2003, L. serriola were planted in the field three weeks after L. sativa cultivars. In 2004, in order to optimize the overlapping of the flowering period, wild plants were planted three weeks sooner than the cultivated, except for those located at $0 \mathrm{~m}$ of trial 2 , which were planted simultaneously with the crop.

Seeds of each individual of the wild species were collected separately every two days, except during rainy days. Due to rather different climatic conditions, the harvesting period was the whole month of July in 2003, while it started in August in 2004.

\section{Plant survival, overlap in flowering time and seed collection}

The average plant survival was much higher in 2004 than in 2003. In 2003, the summer was exceptionally warm and dry in Europe, including Switzerland. A very intensive watering of the plants could only be done in Bevaix, but despite this effort, only $37 \%$ of the plants reached maturity ( 80 plants). In Séprais, where the conditions were even more severe and watering was impossible, only $7 \%$ of the wild plants reached the adult stage (16 plants). Overall, flowering of the two species overlapped poorly.

In 2004, the climatic conditions were optimal for plant growth. However, L. serriola plants in trial 1 were slender, because of the competition by perennial grasses, although nearby surrounding grasses were cut in June. Moreover, the plants located $15 \mathrm{~m}$ north of the crop pollen source in the same field trial suffered from drought and almost all of them died. In total, $65 \%$ of the wild plants reached maturity in Bevaix (144 plants) and 85\% in Séprais (184 plants). Flowering of crop and wild lettuce overlapped completely in both field trials.

\section{Data scoring}

\section{Morphological screening}

At the rosette stage (4 to 5 leaves), L. serriola $\times L$. sativa hybrids look like the paternal $L$. sativa variety and are easily recognizable. At the end of the rosette stage, they are more similar to $L$. serriola, with thicker leaves and a row of spines on the underside of the midrib of the leaves. When hybrid plants start to set seeds, it becomes very difficult to distinguish them from pure wild plants. Their leaves possess a row of spines on the midrib of the underside, and are oriented vertically; the stem becomes prickly. The inflorescence as well is $L$. serriola-like, and the involucral bracts reflex at maturity. Based on this evidence, we morphologically screened the progeny of the wild mother plants at the rosette stage. In 2003, only 96 plants survived in the two field trials, and all their seeds were sown. The total number of seeds sown for 2003 was 44352 , representing an average of 462 seeds/mother plant. In 2004, for the mother plants that set enough seeds, up to 1050 seeds were sown individually, which roughly represents the seed set of 70 capitula (15 florets/capitula), while all the seeds were sown for the plants that set less than 1050 seeds. The total number of seeds sown for that year was 252345 , representing an average of 769 seeds/mother plant (Tab. 1). 


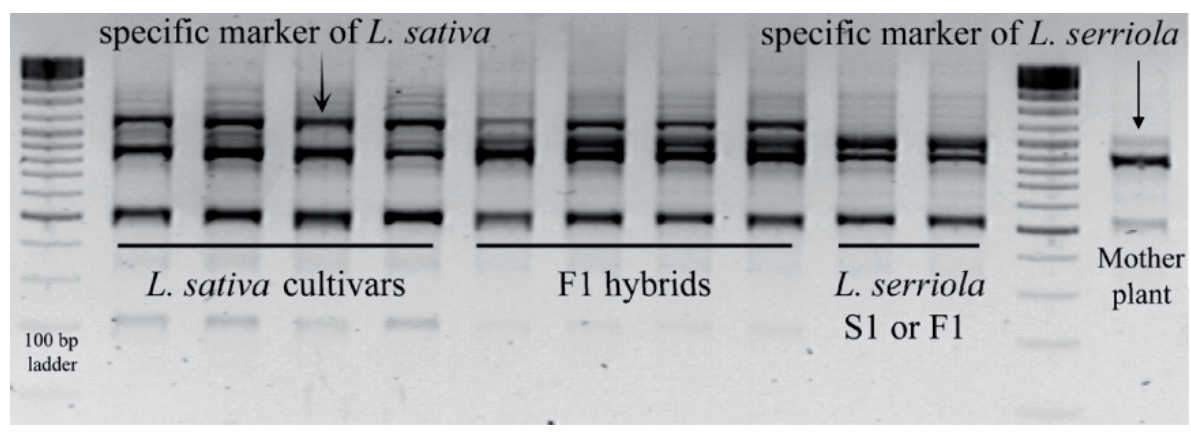

Figure 4. RAPD amplification with primer OPT-06 in the four L. sativa cultivars used in the experiment (pollen source), $4 \mathrm{~F}_{1}$ hybrids, $2 \mathrm{~S}_{1}$ or $\mathrm{F}_{1}$ L. serriola, and 1 L. serriola mother plants (pollen sink). The amplification reveals the presence of specific markers of both, L. sativa and L. serriola in $\mathrm{F}_{1}$ hybrids, while mother plants and $\mathrm{S}_{1}$ L. serriola possess only the fragments specific to the wild species.

Individual hybridization rates (HR) were defined as the percentage of hybrids in the sown progeny of each mother plant, while mean HRs were defined as the average of individual HRs of all the plants in the same row. The incidence of hybridization (IH) was measured as the proportion of $L$. serriola

mother plants producing at least one hybrid. The standard deviation was calculated for each distance respective to the crop pollen source, in each field site and orientation (North and South).

\section{Molecular confirmation of morphological screening}

In order to confirm our hybrid morphological screening, we tested 23 RAPD primers to find specific cultivar markers absent in wild populations of $L$. serriola. Eleven primers, OPB-04, OPB-08, OPB-11, OPC-02, OPC-04, OPC-13, OPC-18, OPP-02, OPP-19, OPT-06 and OPT-07 (Operon technologies, CA-Alameda, USA) produced a total of 17 reliable markers present in the cultivars used and absent from the wild populations (Fig. 4), and were selected for further analysis. Total DNA was extracted from fresh young leaves using QIAGEN ${ }^{\circledR}$ DNeasy Plant Mini Kit. RAPDs amplifications were performed in $25 \mu \mathrm{L}$ final volume, with the following final concentrations: $1 \mathrm{X}$ PCR buffer, $0.2 \mathrm{mM}$ dNTP, $0.4 \mu \mathrm{M}$ primer, $0.75 \mathrm{U}$ Taq polymerase (Qiagen AG, Basel) and 20-40 ng template DNA. Amplifications were carried out in a Biometra T3 thermocycler as follow: $4 \mathrm{~min}$ initial denaturation at $94{ }^{\circ} \mathrm{C}$, then 37 cycles of $93{ }^{\circ} \mathrm{C}$ : $60 \mathrm{~s} ; 41^{\circ} \mathrm{C}$ : $60 \mathrm{~s}$ and $72{ }^{\circ} \mathrm{C}$ : $60 \mathrm{~s}$. Final extension was 5 min at $72{ }^{\circ} \mathrm{C}$. PCR products were mixed with $1 / 3$ volume loading buffer and loaded onto $1.5 \%(\mathrm{w} / \mathrm{v})$ agarose gels stained with ethidium bromide. Electrophoreses were carried out at $100 \mathrm{~V}$.

Fifty plants scored morphologically as wild progenies of $L$. serriola and 50 plants scored as hybrids from 10 dif- ferent mother plants were used to verify the morphological screening. All $50 \mathrm{~F} 1$ hybrids scored morphologically amplified the L. sativa cultivar-specific RAPD markers, while none of the crop markers were amplified in wild S1 or F1 L. serriola (Fig. 4). Thus, we considered morphological screening as reliable, and used it for further detection of hybrids. In order to avoid overestimation of the hybridization rate, all plants whose identification was too doubtful were scored as L. serriola.

\section{Statistical analyses}

As many plants died the first year, HR and $\mathrm{IH}$ were compared between 2003 and 2004 for both sites with Mann-Whitney U tests with SPSS (SPSS Inc., Chicago, Illinois). Bonferroni's correction (Rice, 1989) was applied in order to calculate significance levels adjusted for multiple comparisons performed on the same data set.

Because of the too different sizes of the 2003 and 2004 datasets, further analyses were carried out for 2004 only. As the data did not fit a normal distribution, we used logistic regression analyses on a logarithmic scale to compare $\mathrm{HR}$ and IH between sites and as a function of the distance from the pollen source.

In order to test if the origin of the populations of L. serriola influenced the HR or IH, three logistic regressions were successively carried out while removing one population each time. All the comparisons were not significant. Therefore, the origin of the populations of $L$. serriola was removed from further analyses. Logistic regression analyses were carried out with SAS software (SAS 9.1 Institute Inc., Cary, NC, USA) and graphical representation with S-Plus ${ }^{\circledR}$ (Insightful Corp.) software. 


\section{Pollinators}

While the survey of Lactuca pollinators was not the goal of the study, the most frequent insects active on the flowers were captured in trial 2 and identified. Captures were performed during three sunny days in the morning when pollinator activity was intense.

\section{ACKNOWLEDGEMENTS}

The authors are grateful to Selina and Milo Stoecklin, Angelo, Lidia and Nadia D'Andrea, Christian Ethique, Christophe Mouhay, Isabelle Arpel, Lorraine Martignier, Alexa Oppliger, Thomas Ferrantin for their precious help in the field, Anouk Béguin for her help in the lab and Jacqueline Moret for the statistical analyses. Thanks to Dr. Jason Grant for the English check of the manuscript. We thank also all the employees of the Botanical Garden of Neuchâtel, who made this study possible. The authors are also grateful to Norman Ellstrand, Danny Hooftman and two anonymous reviewers for their helpful comments on the manuscript. This study is part of the EC-funded project "ANGEL" (EU-QLK-CT-200101657). This project was partially funded by the National Centre of Competence in Research (NCCR) Plant Survival, research programme of the Swiss National Science Foundation.

Received August 21, 2007; accepted February 11, 2008.

\section{REFERENCES}

Bateman AJ (1947) Contamination in Seed Crops. 3. Relation with isolation distance. Heredity 1: 303-336

Chen LJ, Lee DS, Song ZP, Suh HS, Lu BR (2004) Gene flow from cultivated rice (Oryza sativa) to its weedy and wild relatives. Ann. Bot. 93: 67-73.

Curtis IS, He C, Jordi W, Davelaar E, Power JB, De Laat AMM, Davey MR (1999) Promoter deletions are essential for transformation of lettuce by the T-cyt gene: The phenotypes of transgenic plants. Ann. Bot. 83: 559-567

De Vries IM (1990) Crossing experiments of lettuce cultivars and species (Lactuca sect. Lactuca, Compositae). Pl. Syst. Evol. 171: 233-248

Durst CE (1930) Inheritance in lettuce. Illinois Agr. Exp. Sta. Bull. 356: 237-341

Eenink AH (1983) Preliminary-results of research on storage and in vitro germination of lettuce pollen as an aid in lettuce breeding. Euphytica 32: 521-526

Ellstrand NC (2003) Dangerous liaisons? When cultivated plants mate with their wild relatives. Baltimore (MD): Johns Hopkins University Press
Frietema de Vries FT (1992) The systematic relationship of Lactuca sativa and Lactuca serriola, in relation to the distribution of Prickly lettuce. Acta Bot. Neerl. 43: 79

Frietema de Vries FT, van der Meijden R, Brandeburg WA (1994) Botanical files on lettuce: on the chance for gene flow between wild and cultivated Lettuce (L. sativa L. including L. serriola L., Compositae) and the generalised implication for risks assessment on genetically modified plants. Gorteria supplement 2: $44 \mathrm{p}$

Goto F, Yoshihara T, Saiki H (2000) Iron accumulation and enhanced growth in transgenic lettuce plants expressing the iron-binding protein ferritin. Theor. Appl. Genet. 100: 658664

Goubara M, Takasaki T (2003) Flower visitors of lettuce under field and enclosure conditions. Appl. Entomol. Zool. 38: 571-581

Goubara M, Takasaki T (2004) Pollination effects of the sweat bee Lasioglossum villosulum trichopse (Hymenoptera: Halictidae) on genic male-sterile lettuce. Appl. Entomol. Zool. 39: $163-169$

Guadagnuolo R, Clegg J, Ellstrand NC (2006) Relative fitness of transgenic vs. non-transgenic maize $\times$ teosinte hybrids: A field evaluation. Ecol. Appl. 16: 1967-1974

Hooftman DAP, Oostermeijer JGB, Jacobs MMJ, den Nijs HCM (2005) Demographic vital rates determine the performance advantage of crop-wild hybrids in lettuce. J. Appl. Ecol. 42: 1086-1095

Hooftman DAP, Jong MJD, Oostermeijer JGB, den Nijs H (2007) Modelling the long-term consequences of crop-wild relative hybridization: a case study using four generations of hybrids. J. Appl. Ecol. 44: 1035-1045

Ibarra Perez FJ, Ehdaie B, Waines JG (1997) Estimation of outcrossing rate in common bean. Crop Sci. 37: 60-65

Jones HA (1927) Pollination and life history studies of lettuce (Lactuca sativa L.). Hilgardia 2: 425-479

Klinger T, Elam DR, Ellstrand NC (1991) Radish as a model system for the study of engineered gene escape rates via cropweed mating. Conserv. Biol. 5: 531-535

Klinger T, Arriola PE, Ellstrand NC (1992) Crop-weed hybridization in radish (Raphanus sativus): effects of distance and population size. Am. J. Bot. 79: 1431-1435

Koopman WJM, Zevenbergen MJ, van den Berg RG (2001) Species relationships in Lactuca s.l. (Lactuceae, Asteraceae) inferred from AFLP fingerprints. Am. J. Bot. 88: 1881-1887

Ladizinsky G (1984) Founder effect in crop-plant evolution. Econ. Bot. 39: 191-199

Lebeda A, Dolezalovà I, Kristkovà E, Mieslerovà B (2001) Biodiversity and ecogeography of wild Lactuca ssp. in some European countries. Genet. Resour. Crop Evol. 48: 153-164

Lebeda A, Dolezalova I, Ferakova V, Astley D (2004) Geographical distribution of wild Lactuca species (Asteraceae, Lactuceae). Bot. Rev. 70: 328-356

Lindqvist K (1960a) Cytogenetic studies in the serriola group of Lactuca. Hereditas 46: 75-151

Lindqvist K (1960c) On the origin of cultivated lettuce. Hereditas 46: 319-350 
McCabe MS, Schepers F, van der Arend A, Mohapatra U, de Laat AMM, Power JB, Davey MR (1999) Increased stable inheritance of herbicide resistance in transgenic lettuce carrying a petE promoter-bar gene compared with a CaMV 35S-bar gene. Theor. Appl. Genet. 99: 587-592

Mejias JA (1994) Self-fertility and associated flower head traits in the Iberian taxa of Lactuca and related genera (Asteraceae, Lactuceae). Plant Syst. Evol. 191: 147-160

Nagata RT, Dusky JA, Ferl RJ, Torres AC, Cantliffe DJ (2000) Evaluation of glyphosate resistance in transgenic lettuce. J. Am. Soc. Hoartic. Sci. 125: 669-672

Nakamaya Y, Yamaguchi H (2002) Natural hybridization in wild soybean (Glycine max ssp. soja) by pollen flow from cultivated soybean (Glycine max ssp. max) in a designed population. Weed. Biol. Manage. 2: 25-30

Okubara PA, Arroyo-Garcia R, Shen KA, Mazier M, Meyers BC, Ochoa OE, Kim S, Yang CH, Michelmore RW (1997) A transgenic mutant of Lactuca sativa (lettuce) with a T-DNA tightly linked to loss of downy mildew resistance. Mol. Plant Microbe In. 10: 970-977

Ownbey M, Andersson IE (1949) Introgressive Hybridization. New York, London

Pammel LH (1918) Prickly lettuce. Proc. Ia. Acad Sci. 20: 109

Paul EM, Capiau K, Jacobs M, Dunwell JM (1995) A study of gene dispersal via pollen in Nicotiana tabacum using introduced genetic markers. J. Appl. Ecol. 32: 875-882

Pileggi M, Pereiara AAM, Silva JD, Pileggi SAV, Verma DPS (2001) An improved method for transformation of lettuce by Agrobacterium tumefaciens with a gene that confers freezing resistance. Braz. Arch. Biol. Tech. 44: 191-196

Prince SD, Marks MK, Carter RN (1978) Induction of flowering in wild lettuce (Lactuca serriola L.). New Phytologist 81: $265-277$

Rice WR (1989) Analyzing tables of statistical tests. Evolution 43: $223-225$
Schmitt J (1983) Density-dependent pollinator foraging, flowering phenology, and temporal pollen dispersal patterns in linanthus-bicolor. Evolution 37: 1247-1257

Snow AA, Palma PM (1997) Commercialization of transgenic plants: Potential ecological risks. Bioscience 47: 86-96

Snow AA, Spira TP (1996) Pollen-tube competition and male fitness in Hibiscus moscheutos. Evolution 50: 1866-1870

Song ZP, Lu BR, Zhu YG, Chen JK (2003) Gene flow from cultivated rice to the wild species Oryza rufipogon under experimental field conditions. New Phytol. 157: 657-665

Thompson RC, Whitaker TW, Bohn GW (1958) Natural cross-pollination in lettuce. Proc. Am. Soc. Hort. Sci. 36: 403409

Van Deynze AE, Sundstrom FJ, Bradford KJ (2005) Pollenmediated gene flow in California cotton depends on pollinator activity. Crop Sci. 45: 1565-1570

Wang TY, Chen HB, Reboud X, Darmency H (1997) Pollenmediated gene flow in an autogamous crop: Foxtail millet (Setaria italica). Plant Breed. 116: 579-583

Watts LE (1958) Natural cross-pollination in lettuce. Nature 181: 1084

Weaver SE, Downs MP (2003) The biology of Canadian weeds. 122. Lactuca serriola L. Can. J. Plant Sci. 83: 619628

Whitaker TW (1939) Cytogenetic observations in Lactuca. $J$. Agri. Res. 58: 297-306

Wolfenbarger LL, Phifer PR (2000) Biotechnology and ecology - The ecological risks and benefits of genetically engineered plants. Science 290: 2088-2093

Zhang NY, Linscombe S, Oard J (2003) Out-crossing frequency and genetic analysis of hybrids between transgenic glufosinate herbicide-resistant rice and the weed, red rice. Euphytica 130: $35-45$ 